\title{
Adaptasi Alat Ukur Emotional Leadership untuk Mengukur Kapabilitas Kecerdasan Emosional Pimpinan Perusahaan di Indonesia
}

\section{Adaptation of Emotional Leadership's Scale for Measuring Company Leader's Emotional Intelligence Capabilities in Indonesia}

\author{
Sekar Ayu Anjani ${ }^{1}$, Airin Triwahyuni ${ }^{2}$, Anissa Lestari Kadiyono ${ }^{3}$ \\ Fakultas Psikologi Universitas Padjadjaran Bandung, Indonesia \\ Email:1sekar13003@mail.unpad.ac.id,2airin.triwahyuni@unpad.ac.id, 3anissa.lestari@unpad.ac.id
}

KATA KUNCI

KEYWORDS

ABSTRAK

ABSTRACT
Emotional leadership, kecerdasan emosi, kapabilitas emosi, kepemimpinan, ELQ

Emotional leadership, emotional intelligence, emotional capabilities, leadership, ELQ

Dalam berdirinya suatu perusahaan, tentu terdapat pemimpin yang mengarahkan geraknya roda dan seluruh sumberdaya di dalamnya untuk mencapai tujuan bersama. Pemimpin yang efektif adalah pemimpin yang mampu mengelola emosinya dengan baik dalam segala kondisi yang dihadapi oleh perusahaan. Keefektifan pimpinan tersebut, lebih besar membutuhkan peranan kecerdasan emosional dirinya daripada kecerdasan secara intelektual. Maka, perlu diketahui bagaimana dinamika dan skala kapabilitas kecerdasan emosional pimpinan agar dapat digunakan sebagai bahan evaluasi dan intervensi. Emotional leadership questionnaire (ELQ) pertama kali dikembangkan di Finlandia pada tahun 2011 dengan 51 butir pernyataan yang belum pernah dilakukan adaptasi dengan Bahasa Indonesia. Adaptasi dilakukan kepada $171(\mathrm{n}=171)$ karyawan yang tersebar di berbagai daerah di Indonesia dengan 111 responden karyawan instansi swasta/non pemerintah dan 60 karyawan instansi BUMN/negeri/pemerintah. Hasil dari adaptasi yang telah dilakukan melalui pendekatan analisis uji classical test theory, confirmatory factor analysis, dan pendekatan item-respond theory menunjukkan bahwa alat ukur ELQ reliabel dan valid dengan kriteria yang baik dengan mengeliminasi empat butir pernyataannya menjadi 47 butir.

In the establishment of a company, there certainly exist a leader who directs the movement of the wheels and all the resources in it to achieve common goals. An effective leader is a leader who is able to manage his emotions well in all conditions faced by the company. The effectiveness of the leader requires a greater emotional intelligence than intellectual intelligence. So, it is necessary to know how the dynamics and scale of the leadership's emotional intelligence capability can be used as evaluation and intervention material. The Emotional Leadership Questionnaire (ELQ) was first developed in Finland in 2011 with 51 statements that have never been adapted to Indonesian language. Adaptation was carried out for $171(n=171)$ employees spread across various regions in Indonesia with 111 respondents being employees of private/non-government agencies and 60 employees of BUMN/public/government agencies. The results of the adaptation obtained through the classical test theory analysis approach, confirmatory factor analysis, and the item-respond theory approach showed that the ELQ measuring instrument is reliable and valid with good criteria by eliminating four statements to 47 items. 


\section{PENDAHULUAN}

Menuju era revolusi industri 5.0, Indonesia sebagai negara yang berkembang membutuhkan adaptasi yang cepat dan tepat. Revolusi industri 5.0 pertama kali dikenalkan oleh Jepang pada tahun 2017 yang kemudian dikenalkan sebagai roadmap yang lebih mudah dipahami sebagai society 5.0 pada tahun 2019 (UNESCO, 2019) untuk mengatasi permasalahan perekonomian negara yang boros akibat biaya perawatan yang besar bagi usia tua di Jepang, sehingga mereka berusaha memanfaatkan teknologi untuk mengatasinya. Revolusi industri 5.0 akan menuntut lingkup perindustrian untuk dapat bekerja secara human centered dengan technology based. Artinya, persaingan di dunia industri nantinya tidak lagi mau menoleransi ketidakpahaman individu yang gagap teknologi.

Usaha organisasi untuk beradaptasi pada revolusi industri yang kian berganti, menyebabkan perubahan-perubahan struktur dan tujuan organisasi yang juga pesat. Hal tersebut menyebabkan pencapaian tujuan organisasi tidak lagi mudah, apalagi jika hanya mengandalkan sumber daya yang terbatas dari segi kompetensi, wawasan, dan keterampilannya. Kondisi di mana organisasi dapat secara efektif mencapai tujuan dan hasil yang diinginkan bersama disebut sebagai efektivitas organisasi (Malik dkk., 2011).

Dalam mencapai efektivitasnya, organisasi sebagai sistem sosial perlu mencapai tujuannya tanpa melumpuhkan sarana dan sumber dayanya, serta tanpa adanya ketegangan antar anggota di dalamnya (Basil \& Arnold, 1969). Salah satu yang menjadi kunci keberhasilannya adalah peran pimpinan di organisasi. Pada model kepemimpinan konvensional, mereka memanfaatkan otoritas mereka untuk mempengaruhi bawahannya, namun saat ini mereka perlu untuk membaur dan menggunakan karismanya dalam mengajak bawahannya bertindak.

Kesediaan karyawan untuk berubah pun bergantung pada bagaimana pimpinan dalam organisasi mampu mempengaruhi mereka untuk melakukan perubahan bersama. Peran pimpinan dalam organisasi bahkan tidak hanya sebatas pada usahanya untuk mempengaruhi karyawannya dalam bertindak dan melakukan perubahan, namun juga untuk menentukan program, sistem manajemen, serta strategi organisasi agar senantiasa mampu bersaing (Yukl, 2008). Menurut Cherniss (2001) atasan yang efektif mampu mengelola emosi mereka, sehingga karyawan dapat mempercayai diri mereka dan merasa nyaman ketika bekerja dengan mereka. Oleh karena itu, kapabilitas emosi pemimpin menjadi salah satu faktor penting keberhasilannya.

Kapabilitas emosi pimpinan atau emotional leadership sendiri didefinisikan oleh Tirri dan Nokelainen (2011) sebagai kecerdasan emosional pemimpin yang dirasakan oleh bawahannya dalam setting bekerja, sehingga emotional intelligence (EI) memang memainkan peranan yang cukup penting pada alat ukur ini. Menurut Goleman (1995) kecerdasan emosional merupakan faktor yang dirujuk memainkan peranan penting dalam menjelaskan keberhasilan seseorang di tempat kerja dan memerankan $80 \%$ kesuksesan kerja individu, dan 20\% sisanya merupakan faktor-faktor lain yang salah satunya adalah kecerdasan intelektual (IQ).

Konsep mengenai emotional kecerdasan emosional Goleman dkk. (2002) yang kemudian diadaptasi oleh Tirri \& Nokelainen (2011) yang membagi kemampuan tersebut menjadi empat dimensi yang mengandung self-awareness, selfmanagement, social awareness, dan relationship management. Tirri dan Nokelainen mengembangkan alat ukurnya dengan nama emotional leadership questionnaire (ELQ) yang terdiri dari 51 butir pernyataan kuesioner. Alat ukur tersebut pertama kali dikembangkan di Finlandia dengan melibatkan 806 responden penelitian pada tahun 2011 untuk mengukur kapabilitas kecerdasan emosional pimpinan di sekolah. 
Alat ukur ELQ merupakan pengembangan dari alat ukur serupa sebelumnya yang mengukur kecerdasan emosional oleh Goleman $(1995,1998)$ untuk mengukur emotional quotation (EQ) individu secara umum menggunakan emotional competence inventory (ECI). Namun, Matthews dkk. (2002) berusaha mengevaluasinya karena adanya beberapa kekurangan seperti tidak adanya analisis faktor dan keterbatasan responden pengukuran EQ individu secara umum (tidak pada setting spesifik tertentu), sehingga kemudian dikembangkan oleh Tirri dan Nokelainen (2011) alat ukur ELQ tersebut yang spesifik dapat digunakan untuk mengukur kapabilitas kecerdasan emosional pimpinan dalam setting bekerja.

Di Indonesia sendiri, konsep emotional leadership berserta alat ukur ELQ belum pernah dikembangkan sebelumnya. Padahal, pengukuran emotional leadership dapat menjadi penting yaitu sebagai penunjang langkah pendekatan yang tepat antara pimpinan kepada bawahannya agar kemudian dapat mencapai tujuannya. Maka, menjadi penting bagi pemimpin mengetahui seberapa besar kapabilitas emotional leadership yang mereka miliki beserta besaran aspeknya.

Selain itu, terdapat kelebihan dari alat ukur ELQ yang mana pengisiannya dilakukan oleh bawahan dari pimpinan itu sendiri. Artinya, bukan pimpinan sendiri yang menilai atas dirinya. Harapannya, hal tersebut juga dapat menguranginya subjektivitas dan normativitas pengisian kuesioner agar menjadi lebih objektif dan valid.

Dengan demikian, maka adaptasi alat ukur ELQ di Indonesia dapat dilakukan untuk. Agar dapat digunakan secara layak di Indonesia pula, maka tujuan dari penelitian ini adalah untuk mendapatkan hasil adaptasi ELQ yang dikembangkan oleh Tirri dan Nokelainen (2011) yang baik dengan menggunakan Bahasa Indonesia dengan reliabilitas dan validitas item dengan butirbutir pernyataan yang baik melalui berbagai macam pengukurannya.

\section{METODE PENELITIAN \\ Partisipan Penelitian}

Partisipan dari penelitian ini adalah seluruh karyawan aktif di perusahaan badan usaha milik negara (BUMN), swasta, pemerintah, non-pemerintah, lembaga, atau instansi lainnya yang memiliki pimpinan atau atasan langsung yang secara langsung yang memegang tanggung jawab atas diri kinerja karyawan tersebut, misalnya tanggung jawab atas hal pelaporanpelaporan dan target pekerjaan. Teknik sampling yang digunakan dalam pengambilan data pada penelitian ini menggunakan non-probability sampling yaitu dengan teknik accidental assignment/sampling.

Pengambilan data dilakukan secara online diambil dari berbagai daerah di Indonesia. Jumlah seluruh partisipan yang mengikuti penelitian dalam rangka adaptasi alat ukur ini adalah sebanyak 171 partisipan. 171 partisipan tersebut terdiri dari 100 orang partisipan berjenis kelamin perempuan dan 71 orang partisipan laki-laki. Partisipan tersebut tersebar pada lebih dari 15 kota/kabupaten yang ada di Indonesia dengan rata-rata masa bekerja 1-5 tahun, 111 di antaranya bekerja di instansi swasta/non pemerintah dan 60 sisanya bekerja di instansi BUMN/negeri/pemerintah.

\section{Prosedur Penelitian}

Prosedur yang dilalui oleh peneliti dengan tujuan adaptasi alat ukur ELQ ini melalui beberapa tahap, yaitu yang pertama adalah tahap persiapan, tahap translasi, tahap expert/peer review, tahap uji coba, tahap pengambilan data mengacu pada prosedur adaptasi berdasarkan ITC Guidelines ("ITC Guidelines for Translating and Adapting Tests Second Edition,” 2017).

\section{Tahap Persiapan Adaptasi}

Pada tahap persiapan, peneliti mengajukan perizinan untuk mengadaptasi alat ukur ELQ pada author dari konsep emotional leadership itu sendiri, yaitu Tirri dan Nokelainen. Setelah mendapatkan izin kemudian peneliti mendapatkan alat ukur 
asli dari author sehingga kemudian dapat langsung dilakukan translasi terhadap konstruk emotional leadership, yaitu translasi pada definisi, dimensi, indikator, dan butir-butir pernyataan yang menyusun kuesioner tersebut. Berdasarkan dari data yang didapatkan dari author, maka sebaran dimensi beserta definisinya dan indikator yang menyusunnya diperjelas pada tabel 1 .

Indikator-indikator tersebut

kemudian turun menjadi butir-butir pernyataan dalam kuesioner sesuai dengan yang telah disusun oleh author sebelumnya.

\section{$\underline{\text { Tahap Translasi }}$}

Agar mendapatkan hasil yang sesuai dengan kondisi perusahaan di Indonesia, tahap pertama proses translasi yang dilakukan adalah dengan melalui proses forward translation oleh dua penerjemah tersumpah untuk kemudian hasilnya disintesis oleh peneliti. Setelah hasil sintesis didapatkan, maka peneliti melakukan kembali proses translasi dengan tahap backward translation oleh dua penerjemah tersumpah. Kemudian, hasil sintesis butirbutir pernyataan oleh peneliti masuk pada tahap uji keterbacaan dan kesesuaian budaya perusahaan di Indonesia melalui expert/peer review oleh seorang dosen ahli di bidang Psikologi Industri dan Organisasi yang memahami konsep mengenai emotional leadership dan tiga orang mahasiswa Psikologi Industri dan Organisasi.

\section{Tahap Expert/Peer Review}

Tahap expert/peer review dilakukan oleh peneliti agar mendapatkan butir pernyataan yang benar-benar sesuai bahasanya dengan konteks budaya perusahaan di Indonesia. Review tersebut dilakukan dengan meminta pendapat dari para ahli dan rekan sejawat peneliti agar memberi masukan apabila didapatkan butir pernyataan yang tidak atau kurang dapat dipahami, memiliki makna ganda atau kemiripan dengan butir lainnya, atau terdapat kata dan kalimat yang mengalami ketidaksesuaian dengan budaya perusahaan yang ada di Indonesia.
Berdasarkan 51 butir pernyataan hasil sintesis peneliti sebelumnya, terdapat 6 (enam) butir pernyataan yang mendapatkan masukan dari para ahli dan rekan sejawat peneliti agar dapat diubah kata-katanya menjadi lebih sesuai dengan konteks budaya di Indonesia. Namun hasil review tidak menunjukkan perlunya butir pernyataan yang digugurkan, maka peneliti kemudian melakukan perbaikan dan sintesis kembali untuk masuk pada tahap uji coba.

\section{Tahap Uji Coba Alat Ukur}

Setelah melalui proses perbaikan dan sintesis kembali pada 51 butir pernyataan kuesioner, kemudian peneliti melakukan uji coba kepada 30 orang karyawan di Indonesia. Berdasarkan hasil uji coba tersebut, didapatkan hasil koefisien reliabilitas cronbach alpha sebesar 0.956 yang mana hasil tersebut menunjukkan bahwa alat ukur valid dan reliabel, sehingga siap untuk dilakukan pengambilan data yang sebenarnya.

\section{Tahap Pengambilan Data}

Pada tahap pengambilan data, peneliti menyebarkan kuesioner secara online untuk mendapatkan data yang lebih meluas pada daerah-daerah di Indonesia yang dilakukan selama kurang lebih 2 (dua) minggu. Partisipan yang mengisi kuesioner tersebut sebelumnya telah mengetahui kriteria khusus yang melekat pada dirinya sehingga Ia dapat melakukan pengisian kuesioner adaptasi alat ukur. Setelah partisipan menentukan bahwa dirinya sesuai dengan kriteria, kemudian Ia akan mengisi informed consent, pengisian identitas, dan pengisian kuesioner yang seluruhnya dilakukan melalui platform Google Forms.

Dalam melakukan pengambilan data, peneliti menetapkan jumlah partisipan penelitian sebanyak 200 orang partisipan. Pada kenyataannya, jumlah partisipan seluruhnya yang mengisi kuesioner tersebut adalah sebanyak 204 orang. Namun atas pertimbangan peneliti untuk mengontrol 
Tabel 1. Blueprint Alat Ukur Emotional Leadership Questionnaire

\begin{tabular}{|c|c|c|c|}
\hline DIMENSI & DEFINISI & INDIKATOR & Nomor Item \\
\hline \multirow[t]{3}{*}{$\begin{array}{l}\text { Self } \\
\text { Awareness }\end{array}$} & \multirow{3}{*}{$\begin{array}{l}\text { Kemampuan pimpinan } \\
\text { untuk mengenali dan } \\
\text { memahami suasana } \\
\text { hati, emosi, dan } \\
\text { dorongan, serta } \\
\text { pengaruhnya terhadap } \\
\text { orang lain }\end{array}$} & $\begin{array}{l}\text { Pimpinan mampu mengendalikan } \\
\text { emosi dan dampak dari emosinya. }\end{array}$ & $1,2,3$ \\
\hline & & $\begin{array}{l}\text { Pimpinan mampu menilai kekuatan } \\
\text { dan batasan diri }\end{array}$ & $4,5,6$ \\
\hline & & $\begin{array}{l}\text { Pimpinan percaya akan kemampuan } \\
\text { dirinya }\end{array}$ & 7,8 \\
\hline \multirow[t]{6}{*}{$\begin{array}{l}\text { Self } \\
\text { Management }\end{array}$} & \multirow{6}{*}{$\begin{array}{l}\text { Kemampuan pimpinan } \\
\text { untuk mengontrol dan } \\
\text { mengarahkan diri dan } \\
\text { suasana hati yang } \\
\text { mengganggu }\end{array}$} & $\begin{array}{l}\text { Pempinan mampu mengendalikan } \\
\text { emosi dan suasana hati yang } \\
\text { mengganggu }\end{array}$ & 9,10 \\
\hline & & $\begin{array}{l}\text { Pimpinan mampu bersikap jujur tanpa } \\
\text { ada hal yang ditutupi }\end{array}$ & 11,12 \\
\hline & & $\begin{array}{l}\text { Pimpinan mampu fleksibel terhadap } \\
\text { perubahan situasi dan hambatan }\end{array}$ & $13,14,15$ \\
\hline & & $\begin{array}{l}\text { Pimpinan memiliki dorongan untuk } \\
\text { mencapai prestasi }\end{array}$ & $\begin{array}{c}16,17,18,19, \\
20\end{array}$ \\
\hline & & $\begin{array}{l}\text { Pimpinan senantiasa menangkap } \\
\text { peluang }\end{array}$ & $21,22,23,24$ \\
\hline & & $\begin{array}{l}\text { Pimpinan mampu melihat sisi positif } \\
\text { dari kejadian/hambatan }\end{array}$ & $25,26,27,28$ \\
\hline \multirow[t]{3}{*}{$\begin{array}{l}\text { Social } \\
\text { Awareness }\end{array}$} & \multirow{3}{*}{$\begin{array}{l}\text { Kemampuan pimpinan } \\
\text { untuk mengidentifikasi } \\
\text { dan memahami } \\
\text { keinginan, kebutuhan, } \\
\text { dan sudut pandang } \\
\text { orang lain (empati) }\end{array}$} & $\begin{array}{l}\text { Pimpinan mampu merasakan, } \\
\text { memahami, dan terlibat dalam emosi } \\
\text { orang lain }\end{array}$ & 29,30 \\
\hline & & $\begin{array}{l}\text { Pimpinan mampu membaca jalan } \\
\text { pikiran organisasi }\end{array}$ & 31,32 \\
\hline & & $\begin{array}{l}\text { Pimpinan mampu mengenali dan } \\
\text { memenuhi kebutuhan orang lain }\end{array}$ & $33, \mathbf{3 4}, 35$ \\
\hline \multirow[t]{6}{*}{$\begin{array}{l}\text { Relationship } \\
\text { Management }\end{array}$} & \multirow{6}{*}{$\begin{array}{l}\text { Kemampuan pimpinan } \\
\text { untuk membangun dan } \\
\text { mengelola hubungan } \\
\text { dengan orang lain, } \\
\text { mengelola perselisihan } \\
\text { dan menjadi } \\
\text { komunikator yang baik, } \\
\text { serta kemampuan } \\
\text { dalam membantu orang } \\
\text { lain berkembang. }\end{array}$} & $\begin{array}{l}\text { Pimpinan mampu membimbing orang } \\
\text { lain dengan visi menarik }\end{array}$ & $36,37,38$ \\
\hline & & $\begin{array}{l}\text { Pimpinan mampu menggunakan } \\
\text { berbagai taktik untuk mempengaruhi } \\
\text { orang lain }\end{array}$ & $39,40,41$ \\
\hline & & $\begin{array}{l}\text { Pimpinan mampu mendukung } \\
\text { kemampuan orang lain }\end{array}$ & $42,43,44$ \\
\hline & & $\begin{array}{l}\text { Pimpinan mampu mengelola orang lain } \\
\text { ke arah yang lebih baik }\end{array}$ & $45,46,47$ \\
\hline & & $\begin{array}{l}\text { Pemimpin mampu menyelesaikan } \\
\text { ketidaksepakatan }\end{array}$ & 48,49 \\
\hline & & Pempimpin mampu mengelola tim & $\mathbf{5 0 , 5 1}$ \\
\hline
\end{tabular}


hasil uji alat ukur, terdapat 33 partisipan yang digugurkan jawabannya karena kriteria tertentu sehingga tersisa 171 partisipan yang tergabung dalam penelitian ini.

\section{Analisis Uji}

Alat ukur yang diadaptasi dalam penelitian ini adalah ELQ yang berupa kuesioner yang terdiri dari 51 butir pernyataan penilaian bawahan terhadap pimpinannya menggunakan skala likert dengan rentang jawaban 1-5, yang berisi pilihan cek lis kesesuaian emosi, sikap, dan perilaku yang sering ditampilkan pimpinan dalam setting bekerja mulai dari skala $1=$ sangat tidak sesuai, $2=$ tidak sesuai, $3=$ raguragu, $4=$ sesuai, dan $5=$ sangat sesuai.

Skor yang digunakan dalam alat ukur ELQ ini adalah skor keseluruhan item atau skor total item. Maka, semakin tinggi skor yang didapatkan oleh atasan berdasarkan penilaian langsung dari bawahannya, maka semakin tinggi tingkat kapabilitas kecerdasan emosional pimpinan di perusahaan tersebut. Kemudian sebaliknya, apabila skor total item yang didapatkan rendah, maka hal tersebut berarti bahwa semakin rendah pula tingkat kapabilitas kecerdasan emosional pimpinan di perusahaan.

\section{Pendekatan Classical Test Theory (CTT)} Uji koefisien cronbach alpha dilakukan untuk menganalisis konsistensi internal alat ukur ELQ secara keseluruhan beserta dimensi penyusunnya, yang mana diketahui berdasarkan kriteria Kaplan dan Sacuzzo (2005) bahwa nilai cronbach alpha alat ukur yang memiliki nilai di atas atau sama dengan 0,70 berarti bahwa alat ukur dapat diandalkan. Diuji pula validitas butirbutir pernyusun alat ukur melalui koefisien corrected item-total correlation pada 51 butir pernyataan yang ada. Hal tersebut diuji berdasarkan kriteria Azwar (1999) yang menyebutkan bahwa butir pernyataan yang mencapai koefisien korelasi minimal 0,30 maka daya pembedanya dianggap memuaskan. Uji analisis CTT ini dilakukan dengan.menggunakan software SPSS versi 25 for Macintosh.

Pendekatan Confirmatory Factor Analysis (CFA)

Uji analisis faktor menggunakan confirmatory factor analysis (CFA) untuk melihat validitas dari konstruk itu sendiri sehingga dapat mencapai model alat ukur yang fit, yaitu butir pernyataan di dalamnya benar memberikan informasi yang sama yaitu konstruk yang akan diukur. Kriteria nilai fit model yang digunakan peneliti mengacu pada kriteria goodness of fit oleh Ferdinand (2005) yaitu dengan kriteria yang dapat dilihat pada Tabel 2. Dalam hal ini pengujiannya dilakukan dengan bantuan software Lisrel.

Tabel 2. Kriteria Goodness of Fit

\begin{tabular}{ccl}
\hline $\begin{array}{c}\text { Goodness } \\
\text { of Fit } \\
\text { Index }\end{array}$ & $\begin{array}{c}\text { Cut Off } \\
\text { Value }\end{array}$ & \multicolumn{1}{c}{ Kriteria } \\
\hline \multirow{2}{*}{ RMSEA } & $\leq 0.08$ & Goodness of Fit \\
\cline { 2 - 3 } & $0.08-0.10$ & Marginal Fit \\
\hline \multirow{2}{*}{ NFI } & $\geq 0.90$ & Goodness of Fit \\
\cline { 2 - 3 } & $0.80-0.89$ & Marginal Fit \\
\hline \multirow{2}{*}{ NNFI } & $\geq 0.90$ & Goodness of Fit \\
\cline { 2 - 3 } & $0.80-0.89$ & Marginal Fit \\
\hline \multirow{2}{*}{ CFI } & $\geq 0.90$ & Goodness of Fit \\
\cline { 2 - 3 } & $0.80-0.89$ & Marginal Fit \\
\hline \multirow{2}{*}{ IFI } & $\geq 0.90$ & Goodness of Fit \\
\cline { 2 - 3 } & $0.80-0.89$ & Marginal Fit \\
\hline
\end{tabular}

Pendekata Item Respond Theory (IRT)

Di samping mempertimbangkan reliabilitas dan validitas item melalui uji menggunakan software SPSS dan Lisrel, peneliti pun menguji validitas item dengan mempertimbangkan abilitas responden dalam menjawab item berdasarkan tingkat kesukarannya. Dengan pendekatan ini, uji dilakukan juga untuk menganalisis interaksi responden dan butir pernyataan sekaligus secara bersamaan, reliabilitas responden dengan butir pernyataan, unidimensionalitas 
alat ukur, bias butir pernyataan, dan ketepatan jumlah respons.

Hal tersebut dianalisis dengan bantuan software Winstep dengan pendekatan Rasch model pada item-respond theory (IRT) sehingga dapat menutupi kekurangan informasi yang didapatkan dari hasil uji model CTT yang mana hasil perhitungannya bergantung pada peserta tes yang mengerjakan tes dan soal yang diujikan.

\section{ANALISIS \& HASIL}

\section{Uji Classical Test Theory (CTT)}

Berdasarkan uji menggunakan metode cronbach alpha untuk mengukur internal consistency dari alat ukur tersebut, maka didapatkan nilai cronbach alpha emotional leadership ini sebesar 0,968. Hal ini menunjukkan bahwa hampir 97\% dari varians observed score merupakan varians true score dan 3\% sisanya merupakan content sampling error. Melihat angka cronbach alpha tersebut, maka dapat diketahui bahwa alat ukur ELQ reliabel dengan internal consistency yang tinggi sehingga dapat diandalkan.

Sedangkan hasil uji validitas berdasarkan butir pernyataan penyusunnya, mengacu pada nilai koefisien corrected-item total correlation didapatkan nilai koefisien corrected-item total correlation pada 51 butir pernyataan yang menyusun kuesioner bernilai antara 0,287-0,778. Artinya, terdapat butir pernyataan yang memiliki nilai daya pembeda yang tidak cukup memuaskan yang mana butir tersebut berada pada butir nomor 12 dan 20 yang berada pada dimensi self management dengan koefisien korelasi 0,289 dan 0,287. Hal ini dapat menjadi pertimbangan pengeliminasian butir pernyataan, namun perlu diperkuat dengan pertimbangan pada analisis uji pendekatan lainnya.

\section{Uji Confirmatory Factor Analysis (CFA)}

Uji CFA yang digunakan oleh peneliti adalah jenis uji second order, di mana menurut (Mayasari dkk., 2020) bahwa second order CFA adalah uji variabel laten yang tidak dapat diukur secara langsung melalui variabel indikatornya, sehingga membutuhkan indikator penyusun yang mana hal tersebut merupakan item indikatornya masing-masing. Hal ini menyebabkan dibutuhkannya pengukuran secara higher atau second order berdasar pada item penyusunnya.

Untuk mendapatkan reliabilitas dan validitas model konstruk yang fit, maka diperlukan beberapa kali tahapan modifikasi model alat ukur. Tahap pertama yang dilakukan peneliti pada model alat ukur adalah dengan menganalisis factor loading item (FL). Suatu item dapat dikatakan memiliki nilai FL yang baik apabila memiliki nilai lebih dari 0,40 (>0,40) (Field, 2013). Berdasarkan kriteria tersebut, didapatkan data bahwa terdapat empat butir pernyataan yang tidak sesuai kriteria yaitu pada butir pernyataan nomor $12,19,20$, dan 27 dengan nilai FL $0,34,0,29,0,24$, dan 0,16 yang seluruhnya berada pada dimensi yang sama yaitu self management, serta didapatkan pula nilai RMSEA dan CFI alat ukur sebesar 0, 104 dan 0,94 yang menunjukkan bahwa model tidak fit seperti pada Gambar 1a.

Setelah mendapatkan hasil analisis tersebut, maka diperlukan modifikasi alat ukur tahap 1 agar mencapai model yang fit dengan mengeliminasi item dengan nilai FL yang di tidak sesuai kriteria, yaitu item nomor 12, 19, 20, dan 27. Dari keempat butir pernyataan tersebut memang diketahui pada model CTT bahwa dua di antaranya (butir 12 dan 20) memiliki pertimbangan pengeliminasian, sehingga didapatkan hasil modifikasi model sesuai pada Gambar 1b.

Sehubungan dengan tujuan peneliti tersebut, setelah melakukan eliminasi item yang tidak memenuhi kriteria, didapatkan nilai RMSEA 0,102 , CFI 0,95 , dan butirbutir pernyataan dengan nilai FL yang seluruhnya memenuhi kriteria minimal yaitu dengan rentang nilai FL sedangkan butir lainnya memiliki nilai FL diantara 0,43-0,83 artinya tidak ada lagi indikasi item yang harus di eliminasi. 
Gambar 1

Diagram model fit alat ukur ELQ
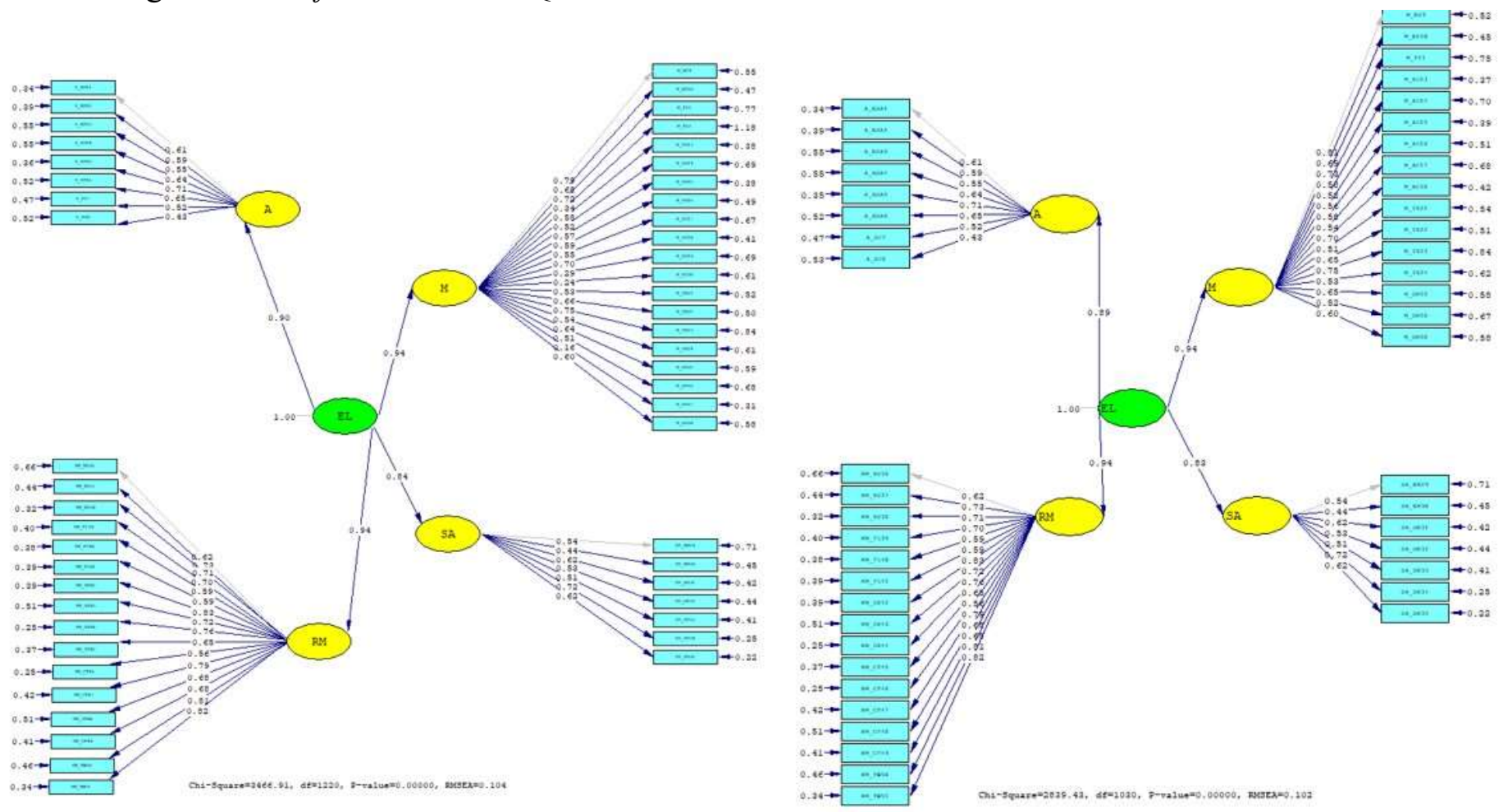

a. Model Fit Tahap 1

b. Modifikasi model fit alat ukur ELQ tahap 1

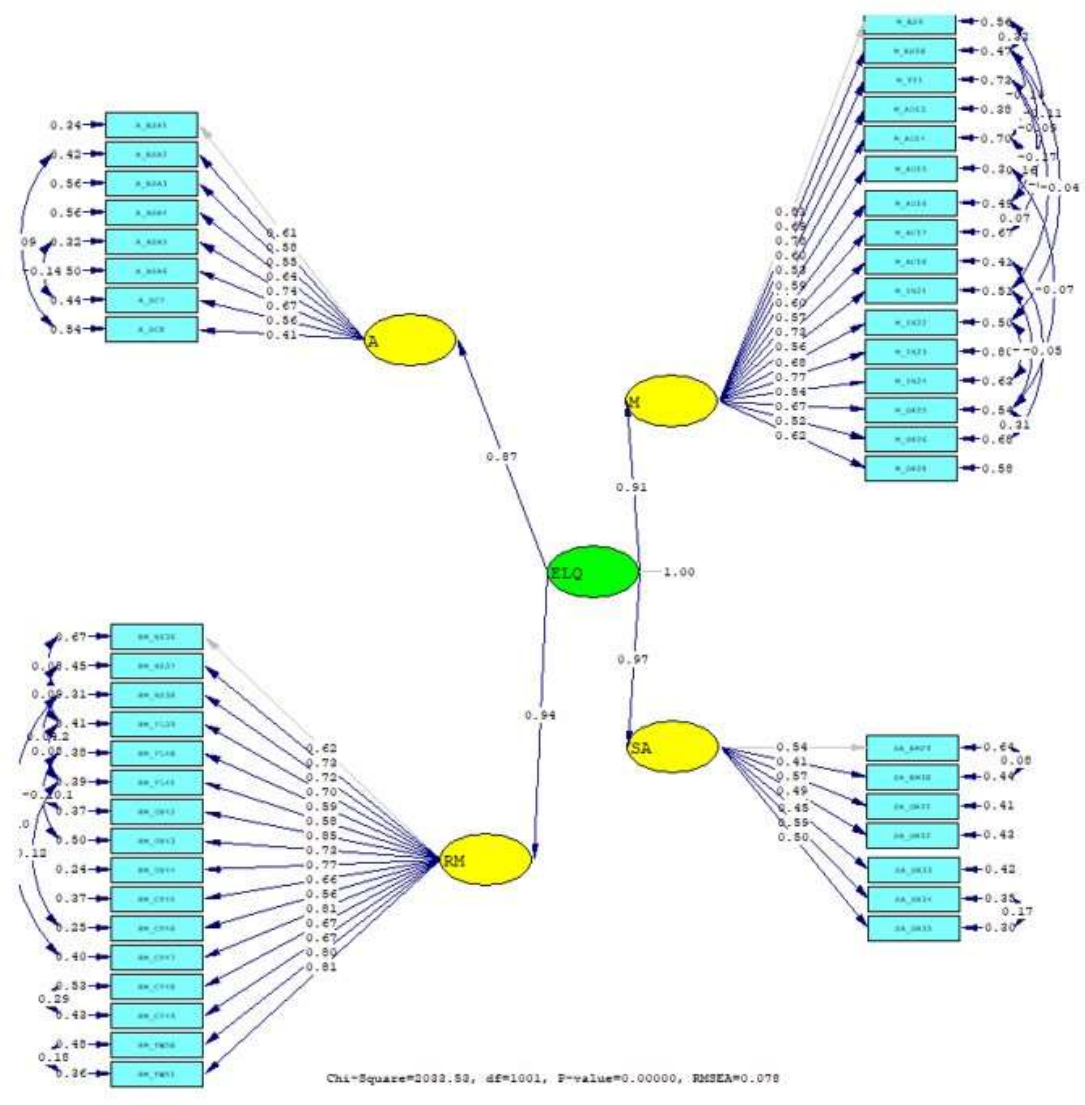

c. Modifikasi model fit alat ukur ELQ tahap 2 
Walaupun diketahui tidak ada lagi butir pernyataan dengan nilai FL yang tidak sesuai dengan kriteria, namun nilai indikasi model fit pada hasil modifikasi tersebut masih belum mencapai kriteria yang fit jika ditinjau dari nilai RSMEA dan CFI nya. Maka selanjutnya peneliti melakukan modifikasi model alat ukur tahap 2 dengan mengorelasikan beberapa butir pernyataan yang terindikasi berkorelasi dengan butir pernyataan lainnya satu sama lain, di dalam setiap dimensi ELQ masing-masing dalam proses CFA. Dengan hal tersebut didapatkan modifikasi model fit alat ukur baru sesuai pada Gambar 1c.

Melalui dua kali tahap modifikasi model fit alat ukur ELQ dengan pendekatan CFA, maka hasil uji sebelum dan sesudah modifikasi dapat dilihat pada Tabel 3 dengan nilai RMSEA 0,078 dan CFI 0,97 yang menunjukkan bahwa model sudah fit dengan nilai FL item yang berkisar di antara 0,410,85 .

Berdasarkan hasil CFA setelah hasil modifikasi tersebut, maka dapat disimpulkan bahwa alat ukur ELQ valid untuk mengukur konstruk emotional leadership dan siap digunakan untuk pengumpulan data berulang yang terdiri dari 51 butir pernyataan tersebar pada 4 dimensi. Selain itu melalui, data di yang diperoleh dari pengambilan data di Indonesia juga memiliki sesuai dengan konsep yang dikembangkan oleh Tirri dan Nokelainen (2011).

\section{Uji Item Response Theory (IRT)}

Pada konsep pendekatan IRT, apabila terindikasi adanya item yang tidak fit berarti bahwa kemungkinan adanya miskonsepsi subjek dalam menjawab soal-soal tersebut. Tingkat kesesuaian item tersebut dianalisis dengan membandingkan nilai outfit meanssquare, outfit z-standard, dan point measure correlation (Boone, Staver, \& Yale, 2014). Menurut mereka, kriteria dalam menilai kesesuaian item tersebut berupa:

1. Nilai outfit mean square (MNSQ) yang diterima sebesar: $0,5<\mathrm{MNSQ}<1,5$

2. Nilai outfit $z$-standard (ZTSD) yang diterima sebesar: $-0,2<$ ZTSD $<+2,0$ Alagumalai, Curtis, dan Hungi (2005)

3. Nilai point measure correlation yang diterima sebesar: $0,4<p t$ measure corr $<0,85$

Namun karena konsep dari penilaian point measure correlation serupa prinsipnya dengan korelasi point-biserial pada CTT, maka Alagumalai dkk. (2005) mengklasifikasikan nilai point measure correlation tersebut ke dalam beberapa kriteria dimana apabila nilai point measure correlation adalah $>0,40$ dikatakan item sangat bagus; $0,30-0,39$ item bagus; 0,20 0,29 item cukup bagus; $0,00-0,19$ item tidak mampu mendiskriminasi; $<0,00$ maka harus dilakukan pemeriksaan terhadap item.

Dengan tujuan tersebut, maka peneliti melakukan analisis kesesuaian item berdasarkan pendekatan Rasch model pada software Winstep dengan analisis output tabel item fit order dan didapatkan hasil misfit order berdasarkan model alat ukur yang utuh terdiri dari 51 butir pernyataan. Jika dianalisis satu-persatu, apabila menganalisis berdasarkan nilai outfit MNSQ dan ZTSD terindikasi bahwa terdapat

Tabel 3. Perbandingan Hasil Uji CFA Sebelum dan Sesudah Modifikasi

\begin{tabular}{|c|c|c|c|c|c|c|}
\hline $\begin{array}{l}\text { Goodness } \\
\text { of Fit } \\
\text { Index }\end{array}$ & $\begin{array}{c}\text { Hasil Uji } \\
\text { Index of Fit } \\
\text { Sebelum } \\
\text { Modifikasi } \\
\end{array}$ & Kriteria & $\begin{array}{c}\text { Hasil Uji Index } \\
\text { of Fit } \\
\text { Modifikasi } \\
\text { Model Tahap I }\end{array}$ & Kriteria & $\begin{array}{c}\text { Hasil Uji Index } \\
\text { of Fit } \\
\text { Modifikasi } \\
\text { Model Tahap } 2\end{array}$ & Kriteria \\
\hline RMSEA & 0,104 & Marginal Fit & 0,102 & Marginal Fit & 0,078 & Geoduess of Fit \\
\hline NFI & 0,91 & Geodness of Fit & 0,92 & Goedness of Fit & 0,94 & Geoduess of Fit \\
\hline NNFI & 0,94 & Gooduess of Fit & 0,95 & Goedness of Fit & 0,96 & Goodness of Fit \\
\hline CFI & 0,94 & Goodusss of Fit & 0,95 & Goedness of Fit & 0,97 & Goodness of Fit \\
\hline IFI & 0,94 & Geodness of Fit & 0,95 & Goodness of Fit & 0,97 & Goodness of Fit \\
\hline
\end{tabular}


beberapa item yang tingkat kesesuaiannya kurang baik, maka barulah dilakukan pertimbangan eliminasi lebih lanjut.

Hal ini memperkuat pertimbangan peneliti pada analisis berdasarkan pendekatan CTT dan CFA sebelumnya untuk mengeliminasi item dengan nomornomor tersebut, walaupun apabila mengacu pada kriteria kesesuaian item Alagumalai dkk. (2005) secara umum item yang menyusun alat ukur ELQ masuk dalam kriteria kesesuaian item yang bagus dan sangat bagus dengan rentang nilai 0,47 0,68 .

Agar menutupi kekurangan dari uji CTT dengan SPSS sebelumnya, melalui Rasch model juga dapat dianalisis konsistensi dari alat ukur ELQ. Hal tersebut

\section{DISKUSI}

Hasil pengujian reliabilitas dan validitas terhadap konstruk berdasarkan butir-butir pernyataan yang menyusunnya didapatkan bahwa hasil adaptasi alat ukur ELQ di Indonesia dikatakan valid dan reliabel. Jika dibandingkan dengan hasil uji reliabilitas yang dilakukan pada pengembangan alat ukur ELQ pertama kali oleh Tirri dan Nokelainen (2011), didapatkan hasil reliabilitas alat ukur cronbach's alpha sebesar 0,810 dengan nilai koefisien korelasi 0,610-0,920 yang menunjukkan bahwa adaptasi alat ukur di Indonesia bahkan mendapatkan nilai reliabilitas cronbach's alpha yang lebih tinggi, walaupun terdapat beberapa butir pernyataan yang memiliki nilai koefisien korelasi jauh lebih rendah dari alat ukur aslinya.

Rendahnya nilai koefisien korelasi dan nilai FL butir pernyataan pada CFA menimbulkan dugaan peneliti adanya ketidaksesuaian hasil penerjemahan baik secara forward maupun backward translation, sehingga mungkin dapat menimbulkan ambiguitas atau makna ganda antar satu butir pernyataan dengan pernyataan lainnya.

Jika mengacu pada kriteria validitas item maka terdapat empat butir pernyataan dilakukan melalui uji reliabilitas interaksi person-item. Dari hasil uji didapatkan reliabilitas person adalah sebesar 0,94 dan reliabilitas item adalah 0,93 yang mana artinya keduanya termasuk dalam kategori alat ukur bagus sekali menurut Sumintono \& Widhiarso (2014). Hal ini berarti bahwa interaksi antara responden dan item bagus sehingga instrument dapat dipercaya untuk digunakan sebagai alat pengumpul data.

Dari uji tersebut juga didapatkan perhitungan didapatkan nilai mean square person adalah 1,42 dan mean measure item adalah 0,00 yang berarti berada pada lebih besar atau sama dengan 0,0 nilai logit sehingga berarti bahwa abilitas atau kemampuan responden lebih besar daripada tingkat kesukaran item.

yang memiliki nilai validitas yang rendah. Berdasarkan indikasi tersebut melalui pertimbangan hasil uji analisis data dengan CTT, CFA, dan IRT maka peneliti memutuskan untuk mengeliminasi empat butir pernyataan tersebut dengan nomor item 12, 19, 20, dan 27 yang berada pada dimensi self management agar nilai validitas alat ukur lebih tinggi. Maka, hasil adaptasi ELQ di Indonesia disusun atas 47 item yang tersebar pada empat dimensi penyusunnya

Di samping itu, keunggulan dari adaptasi alat ukur ELQ ini adalah bahwa dari 47 butir pernyataan memiliki nilai validitas dengan kriteria yang baik apabila dianalisis melalui koefisien korelasi, FL, dan interaksi person-item-nya. Berdasarkan uji model alat ukur terhadap konstruk yang diukur juga menunjukkan bahwa adaptasi tersebut mencapai kriteria goodness of fit dari beberapa acuan kriteria goodness of fit index yang dipaparkan oleh Ferdinand (2005).

\section{SIMPULAN}

Alat ukur ELQ merupakan suatu instrumen yang dapat digunakan untuk mengukur kapabilitas kecerdasan emosional pimpinan pada perusahaan dalam setting bekerja. Dalam hal ini, alat ukur diadaptasi dalam Bahasa Indonesia berdasar teori emotional leadership yang terdiri dari 
dimensi self awareness, self management, social awareness, dan social management.

Berdasarkan hasil uji konsistensi internal, analisis faktor konfirmatorik, dan analisis respons item maka didapatkan adaptasi alat ukur ELQ dalam Bahasa Indonesia sebagai instrumen yang reliabel dan valid, serta siap digunakan lebih lanjut.

Kecerdasan emosional ini akan menjelaskan bagaimana seseorang mampu untuk memahami orang lain, mengekspresikan emosi dan mengelola emosinya sendiri, juga orang lain. Pemimpin yang efektif juga merupakan pemimpin yang mampu memimpin dengan segala ucapan, perbuatan dan sikap atau perilaku hidup yang mendorong dan mengantarkan bawahan pada tujuan yang hendak dicapai (Suryana, 2019). Seluruh bentuk sikap, perbuatan, dan perilaku dari pemimpin dapat dikontrol melalui emosinya. Hal ini menyebabkan, kapabilitas kecerdasan emosional seorang pemimpin pantas dinilai langsung dari pengalaman bawahannya dengan alat ukur ELQ.

\section{SARAN}

Diketahui berdasarkan penelitian yang telah dilakukan bahwa terdapat keterbatasannya. Pertama, bahwa saran uji confirmatory factor analysis (CFA) yang baik adalah dengan melibatkan jumlah responden sebanyak 300, sedangkan dalam penelitian ini jumlah responden terbatas sejumlah 171 karyawan yang menilai atasannya sehingga hal tersebut dapat dianalisis lebih lanjut apakah menjadi faktor penyebab tidak stabilnya hasil analisis pada uji CFA yaitu dengan menambah jumlah responden.

Kedua, banyaknya saran modifikasi korelasi antar item di dalam dimensi self management pada uji CFA dapat dianalisis lebih lanjut faktor penyebabnya yang mana memungkinkan butir pernyataan di dalamnya mengukur hal yang sama pada indikator yang berbeda. Kurang tepatnya hasil translasi pernyataan yang menimbulkan ambiguitas ataupun makna ganda antar satu butir pernyataan dengan pernyataan lain juga perlu diteliti lebih jauh sehingga dapat meningkatkan nilai validitas yang lebih tinggi dengan mempertahankan seluruh butir pernyataan yang ada.

Saran lainnya juga dapat diberikan dengan menambah proses try out alat ukur dan cognitive interview terhadap responden pada setiap proses try out alat ukur memungkinkan ketepatan makna yang dituju pada butir-butir pernyataan penyusun alat ukur ELQ.

\section{DAFTAR PUSTAKA}

Alagumalai, S., Curtis, D. D., \& Hungi, N. (2005). Applied rasch measurement: $A$ book of exemplars. Springer.

Azwar, S. (1999). Reliabilitas dan Validitas. Sigma Alpha.

Basil, S. G., \& Arnold, S. T. (1969). A study of organizational effectiveness. Personnel Literature, 28(01), 534-540.

Boone, W. J., Staver, R. J., \& Yale, S. M. (2014). Rasch Analysis in the Human Sciences. Springer.

Cherniss, C. (2004). Intelligence, emotional. Encyclopedia of Applied Psyhcology, 2, 315-321.

Ferdinand, A. T. (2005). Structural Equation Modelling. Badan Penerbit Universitas Diponegoro.

Field, A. (2013). Discovering Statistics using SPSS (4th ed.). SAGE.

Goleman, D. (1995). Emotional intelligence. Bantam Books.

Goleman, D. (2013). What makes a Leader: Why Emotional intelligence matters? More than sound.

Goleman, D., Boyatzis, R., \& McKee, A. (2002). Primal Leadership: Realizing the Power of Emotional Intelligence Tapping into Your Team's Emotional Intelligence. Harvard Business Review.

ITC. (2017). Internation Testing Commision (ITC) guidelines for translating and adapting tests (second edition). International Journal of Testing, 1-34. https://doi.org/DOI: 10.1080/15305058.2017.1398166 
Kaplan, R. M., Saccuzo. (2005). Psychological Testing : Principles, Applications, and Issues (6th Edition). Belmont: Wadsworth.

Malik, M. E., Ghafoor, M. M., \& Naseer, S. (2011). Organization effectiveness: a case study of telecommunication and banking sector of Pakistan. Far East Journal of Psychology and Business, 02(1), 37-48.

Matthews, G., Zeidner, M., \& Roberts, R. D. (2002). Emotional Intelligence: Science and Myth. Massachusets: MIT Press.

Sumintono, B., \& Widhiarso, W. (2014). Aplikasi Model Rasch untuk Penelitian Ilmu-ilmu Sosial (Edisi Revisi). Cimahi: Trim Komunikata Publishing House.

Suryana. (2019). Pentingnya Kecerdasan Emosi bagi Kepemimpinan yang Efektif di Era
Milenial Industri 4.0. Jurnal Inspirasi, 10(April), 78-97.

Tirri, K., \& Nokelainen, P. (2011). Measuring Multiple Intelligences and Moral Sensitivities in Education. Boston: Sense Publishers.

UNESCO. (2019). Japan pushing ahead with Society 5.0 to overcome chronic social challenges.

https://en.unesco.org/news/japanpushing-ahead-society-50-overcomechronic-social-challenges

Yukl, G. (2008). How leaders influence organizational effectiveness. The Leadership Quarterly, 19, 708-722. https://doi.org/10.1016/j.leaqua.2008.09. 00 